\title{
GCU
}

Glasgow Caledonian

University

University for the Common Good

\section{Exploring collaboration within social housing retrofit practice for an ageing population: a single case study in the West of Scotland}

Rodger, Dayna ; Callaghan, Nicola; Thomson, Craig

Published in:

Journal of Financial Management of Property and Construction

DOI:

10.1108/JFMPC-04-2020-0020

Publication date:

2021

Document Version

Author accepted manuscript

Link to publication in ResearchOnline

Citation for published version (Harvard):

Rodger, D, Callaghan, N \& Thomson, C 2021, 'Exploring collaboration within social housing retrofit practice for an ageing population: a single case study in the West of Scotland', Journal of Financial Management of Property and Construction, vol. 26, no. 1, pp. 126-140. https://doi.org/10.1108/JFMPC-04-2020-0020

\section{General rights}

Copyright and moral rights for the publications made accessible in the public portal are retained by the authors and/or other copyright owners and it is a condition of accessing publications that users recognise and abide by the legal requirements associated with these rights.

Take down policy

If you believe that this document breaches copyright please view our takedown policy at https://edshare.gcu.ac.uk/id/eprint/5179 for details of how to contact us. 


\title{
Exploring collaboration within social housing retrofit practice for an ageing population: A single case study in the West of Scotland
}

\author{
Purpose: Sustainably addressing the social and economic demands from an ageing \\ population is a major global challenge, with significant implications for policy and \\ practice. This is resultant of the increasing demand for housing adaptations to prevent \\ increased pressure upon acute health services. Through the lens of institutional \\ theory, this research explores the levels of joined-up retrofit practice within a \\ Scottish social housing provider, under a constructivist approach.
}

Design/methodology/approach: An exploratory single case study of a Scottish local authority was undertaken. Within this nine key stakeholders were interviewed, taking a hierarchical approach, from director to repair and maintenance staff. Results were analysed by utilising Braun and Clarke's six stages of thematic analysis.

Findings: There is a need for greater levels of integration within retrofit practice, not only to improve the health and wellbeing of the older population, but to increase efficiency and economic savings within public services. Currently, there are key issues surrounding silo-based decision-making, poor data infrastructure, power struggles and a dereliction of built environment knowledge and expertise, preventing both internal and external collaboration. However, housing, energy and health have interlinking agendas which are integral to achieving ageing in place. Therefore, there must be system wide recognition of the potential benefits of improved cross-sector collaboration, preventing unintended consequences whilst providing socioeconomic outcomes.

Originality: This research provides a new perspective surrounding retrofit practice within the context of an ageing population. It highlights the requirement for improved cross sector collaboration, and the social and economic cost of poor quality practice.

Keywords: Ageing population; Case study; Collaboration; Constructivism; Energy efficiency; Health; Institutional theory; Local authority; Neoliberalism; Retrofit; Social housing. 


\section{Introduction}

Whilst environmental health is closely related to and affected by socioeconomic status, public health research has given less attention to the complex relationship between housing and health within retrofit practice and the implications of this upon policy improvement (Van Hees et al., 2017). Housing as part of health improvements is often implicit within policy. However, unlike health interventions, the main aim of housing adaptations is not the improvement of an individual's health (Youm and Fejock, 2019). Therefore, a need is emerging to examine the nexus between the energy, health and housing sectors, determining the practical implementation of the 'Ageing in Place' agenda through collaboration and knowledge share within housing improvements. A holistic, multidimensional approach is required to account for the social, economic, environmental and institutional aspects of sustainability, and must not focus solely upon the consumption of resources. For example, within the 'Care and Repair' scheme, the services provided include removing damp, providing and replacing heating sources and adapting for mobility needs. By working closely with housing, health and social care the Care and Repair program is an exemplar of holistic retrofit practice, aiding in preventing admission to hospital and increasing discharge speed (Care and Repair, 2013).

This paper presents the second phase of research undertaken to evaluate the success of collaborative efforts within social housing to perform retrofit practice for the improved wellbeing of an ageing population. Within the first phase, 24 interviews were undertaken with key stakeholders across governance, housing, energy and health to determine the key trends and barriers to joined-up retrofit practice. Within this, it emerged that the diffused structures of governance coupled with the government's neoliberal ideological approach created a significant disconnect with regards to collaboration and knowledge sharing between housing, health and energy sectors. This has resulted in a reluctance to take on institutional responsibility (Heald and Steel, 2018) and inhibits the potential for joined-up practice whilst potentially creating greater dependency on state through increased reliance on key national resources such as the NHS. This first phase of research created the need to undertake focused research within the practical setting of a social housing provider (SHP) to explore the emergent themes. Therefore, presented are the findings of an in-depth case study of a SHP in the West of Scotland, through analysis of nine hierarchical stakeholder interviews, determining the successes and failures to create integrated retrofit practice.

\section{Background and literature review}

\section{Theoretical framework}

Institutions are networks through which political interests interact and compete, therefore shaping and constraining subsequent policy and practical choices (Hall and Taylor, 1996). Therefore, institutional theory is vital in explaining how organisations are influenced by their social, economic and political environments (DiMaggio and Powell, 1983). Utilising the concepts of isomorphism (Hawley, 1968) it explains the constraining processes that force organisations to resemble one another. Thus, developing structural rules and procedures which do not necessarily improve efficiency, but gain the appearance of being legitimate to external parties (Abdul-Aziz et al., 2010). Within this research, institutional theory provides a lens to analyse decision-making and examine the broader implications of power struggles which enable or prevent 
collaboration and knowledge sharing within integrated retrofit practice in social housing.

\section{The importance of housing and retrofitting}

A major global challenge is efficiently and sustainably addressing the social and economic demands arising from an ageing population. An ageing population has significant implications for public policy encompassing health, housing and welfare amongst others. Both housing and health policy promote the idea of 'home' as the best place to grow old, with the option of moving to specialist accommodation to be avoided for as long as possible. Ageing in place, or 'the ability to live in one's own home for as long as confidently and comfortably possible' is the ability to be self-reliant at home for as long as it is viable (Shelter, 2007). As people age, declining mobility and illness can result in their residence becoming unsuitable without support or adaptation, often forcing individuals to move into specialist accommodation (Van Hees et al., 2017). However, another key challenge is the prevention of the ageing and deterioration of the housing stock. Energy efficiency improvements made to buildings is considered to be one of the most effective measures to reduce carbon emissions, especially in those which are characterised by poor energy performance (Yazdani et al., 2018; Saidur, 2009). Reducing the exposure of older residents to cold housing and providing access to affordable warmth is a key priority in defeating health issues associated with poor housing conditions (Ofori-Boadu et al., 2017). Therefore, to achieve sustainability, there must be an understanding that human health and the built environment are both inextricably linked.

\section{The need for integration within retrofit practice}

The term retrofit is used to describe a range of activities involved in the repair, improvement and maintenance of buildings; incorporating innovations which directly shape energy use or influence user behaviour (Buser and Carlsson, 2016). However, in the context of this research it is used to describe all alternations to the internal or external building, including ramps and wet floor showers. With an ageing population, great challenges are presented due to increasing acute and long-term requirements. However, many social care and health experts have confessed the lack of linkages within, and understanding of, housing practice which has meant older people's needs have not been holistically considered or prioritised (Zhang et al., 2018). Energy efficiency adaptations affect and are affected by a wide range of policy domains including housing, construction, environmental, health and fiscal policy. However, across these various levels of policy and decision-making, there are diverse agendas and actors with different needs, methods and priorities, creating substantial barriers. It has been suggested that collaborative or partnership working brings a multitude of perceived benefits to all parties involved (Bresnen, 2010) including increased productivity, reduced costs, time and a reduction within industry fragmentation (Smiley et al., 2014; Haveri et al., 2009). Nonetheless, despite enthusiasm from policy makers, this new way of working has yet to materialise (Everingham et al., 2012; Bresnen, 2010).

It is acknowledged that there are key institutional and political restrictions shaping partnership working within and across organisations such as hierarchies, power, inequality and vested interests, particularly within capitalist societies (Smiley et al., 2014). However, there is a need for a holistic retrofit system which takes account of the 
varying needs of older people, creating a practice focused on all aspects of the resident's domestic environment: of habitability, safety and accessibility, especially for older people. Thus, aligning national housing, energy and health policy into a cost efficient practice with wider fiscal and societal benefits such as reduced pressure on primary health care.

\section{Neoliberalism within public services}

Framed by a sustained period of austerity, as a consequence of the 2007/8 financial crisis, the UK and much of Europe have experienced public spending cuts which were ideologically placed upon the most disadvantaged within society (Murphy and Jones, 2016; Suttor, 2011). However, the restructuring and reduced investment of the public sector began in the 1970's with the emergence of New Public Management (NPM); driven by the belief that the public sector was inherently inefficient, monopolistic and a drain on public financing (Hood, 1991). This restructuring of social housing and wider public services gave rise to a fragmented system, with privatisation, including subcontracting work and competitive bidding, leading to institutional, organisation and managerial changes (Krøtel, 2015; Mullins et al., 2001).

UK governance have not protected social housing, with all state and not-forprofit housing providers adhering to neoliberal practices such as competition, hierarchy and public/private partnerships (Jacobs et al., 2013). The rationale behind these modernisation initiatives is constructing the appearance that services can improve during a time of reduced investment and resources (Jacobs et al., 2013). However, these traditions of care are threatened by the growing commercialisation of state services, centred upon investment and asset management, rather than the wellbeing of the vulnerable (Power and Bergan, 2018). Yet, partnership working between different areas of the public, private and voluntary sector is seen as a way of potentially improving services, especially where there is commonality of interest and a history of failing to coordinate services effectively (Rummery, 2009). With the collective agendas formed to support an ageing population, there is a need for social housing, the energy sector and health and social care providers to work together to support adaptation of the housing stock and ensure its long-term asset management (Boyle and Thomson, 2016).

\section{Institutional structures}

The 'rolling back of the state' within UK government policies is perceived to have created an irreversible reduction within the role of public sector institutions. Furthermore, the introduction of market competitiveness through the emergence of NPM exacerbated the government's inability to direct and develop multi-agency arrangements, focusing on target driven, rather than cooperative progress (Hood, 1991). This concept of strategic management and modernisation have become key to organisational effectiveness; emphasising the importance upon structures and its hierarchically regulated public sector (Krøtel, 2015; Mullins et al., 2001). Within this context, policy evaluation can be understood to be a means of providing evidence to legitimise policies and political commitments, rather than completing the policy cycle and providing feedback to improve policy design (Rasmussen et al., 2017; Sanderson, 2002). Thereafter, this process leads to the marketisation of functions, traditionally held within public sector, transforming policy-making away from joint programmes led by an active governance (Rasmussen, et al., 2017). This can be represented within social housing's hierarchy and coordinating systems which are based on the principles of 
command and control, creating clear specification of roles, responsibilities and functions, with formalised communication and reporting procedures (Mullins et al., 2001). Therefore, tying in with the increased influence of managerialism and modernisation linked with privatisation, marketisation and contracting out policies; creating the appearance of success whilst not always selecting the most efficient processes (Mullins et al., 2001). Thus, institutional theory is utilised in analysing the influence of hierarchical structures and the normalisation of neoliberal concepts within the practical implementation of an integrated retrofit practice in line with a global agenda of Ageing in Place.

\section{Data collection and analysis}

\section{Research design}

Within this research, an exploratory single case study approach was adopted. This approach enables the researcher to closely examine the data within a specific context, investigating contemporary real life phenomenon through the contextual analysis of an environment (Yin, 2009). The limitations of a single case study are acknowledged, with multiple case studies creating more robust insights in a wider context (Yin, 2009). However theoretical explanations of the data observed within this paper are applicable across similar state housing providers across Scotland and the UK. Moreover, this research builds upon the work of Boyle and Thomson (2016), which sought alignment between housing and health through an in-depth case study of a state SHP within close proximity of the one represented within this research; facing many of the same issues of an ageing population and fragmented services. Thus, this positioning allows for analysis of how key institutions maintains and directs the integration of retrofit practice under the Ageing in Place agenda, informing future exploration into practice in varying contexts.

\section{Data source}

Following the first phase of research, it was determined vital to gauge an in-depth and practical understanding of the interconnection of retrofit practice within and across the different sectors of public services. Therefore, due to the positioning of Local Authority (LA) social housing which is publicly funded and directed by central government, there is a hypothetical ease of collaboration and joint-working (Ejiogu et al., 2018). Furthermore, as LA's holds 314,482 (53\%) of all social housing within Scotland, it is the key and dominant housing provider and integral to understanding retrofit practice and alignment to national policy (Scottish Government, 2018).

Some key factors in selecting this LA for a case study research are showcased below in Table 1.

Insert: Table 1: Key facts for case study selection.

Within the LA, one in five houses are social housing with the SHP maintaining 8181 homes, representing 16\% of the housing stock and the remaining 9 RSL's maintaining a total of 2179 homes, equivalent to $4 \%$ of the stock. Yet, this is a fairly large state social housing provider, contrasted with national figures whereby $13 \%$ of the population rent from LA's, and 11\% from RSL's. This is indicative of the dependence upon this SHP within the area, making their decision-making and practice highly influential to the successful health and wellbeing of the community, and making it a key 
area for investigation. Within this SHP, 94.3\% of the stock met the Energy Efficiency for Social Housing (EESH) standard. However, 18,000 (35\%) of the population live within fuel poverty, with $9 \%$ in extreme fuel poverty and within this, pensioners are the worst affected. Moreover, the LA has substantial issues surrounding an ageing population compared to the rest of Scotland (rScotland). In 2016, 24\% of the population was aged $65+$, compared to $18 \%$ rScotland, and it is estimated this figure will increase to $32 \%$ by 2039 , compared to $24 \%$ across the nation.

There are fundamental problems surrounding delayed discharge within the LA, whereby in 2016/17, the number of bed days occupies by patients aged 75+ was 1,273 per 1,000 population, compared to the national figure of 842 . Thus, showcasing high levels of dependency upon acute health services, pushing the requirement for a safe and hospitable home environment. As people age, declining mobility and illness related to ageing can mean that their residence is no longer suitable without support or adaptation. Major adaptations such as the installation of a wet room, ramp, widened doorway, cavity wall insultation for affordable warmth or the lowering of structures within a home can have a significant impact on the quality of their health and their wellbeing (Wane, 2016). Thereafter preventing accidents such as falls which may result in admission to hospital, bed blocking, delayed discharge or continual readmission if discharged to a home which does not foster improved health outcomes.

A key tool within the selection of this LA was the SIMD: the Scottish Government's tool for identifying areas of deprivation for policy implementation (SIMD, 2016). Therefore, as this LA has nineteen zones within Scotland's 15\% most deprived areas, affecting 12,888 people, with areas falling within the worst $0-5 \%$ of deprived data zones and with $12.4 \%$ of the population living in the $15 \%$ most deprived zones within Scotland (SIMD, 2016), it is a key area of focus. Moreover, as aforementioned, due to the innately political position of state social housing it is important to note the political positioning within. Having a Conservative and Labour coalition has the potential to create political fragmentation, with opposing views, priorities and investment plans compared to central governance. This is noted as this research focuses heavily upon public services, and when looking at the integration and joint-working between housing, energy and health sectors.

\section{Sample size}

Purposeful sampling was undertaken within this research. By interviewing a wide range of stakeholders, at multiple levels, it leads to richer, more reliable emergent theory (Eisenhardt, 1989). Interviews lasted between 42-93 minutes. In total, 13 stakeholders were contacted, with 9 providing written consent to participate. Their demographic details are displayed in Table 2, aided by Mintzberg's organisational structure theory (1993). The term organisational structure refers to the formal arrangement between individuals and groups with regards to allocation of tasks, responsibilities and authority (Galbraith, 1987). However, these variables are coupled with growth rates and power distribution which impact organisational structure (Luneburg, 2012; Miles et al., 2011). Figure 1 displays the key parts of an organisation.

Insert Table 2: Interview Participants

Insert Figure 1. Key parts of an organisation (Mintzberg, 1993)

Initially individuals were selected due to their prominence within the organisation, for example Councillor C1 created the Housing and Community Wellbeing portfolio. From this, a snowball sampling method was employed, where 
interviewees recommended individuals they believed would be fundamental. Figure 2 displays the hierarchy of individuals and interconnections within their positions. Data collection took place until saturation was achieved and no new themes emerged. The function of these interviews was to gauge a full understanding of the decision-making and levels of integration between different retrofit agendas within social housing.

Insert Figure 2: Interview Participants Hierarchy

To ensure coherence and consistency, a standard interview guide containing questions and probes was created to guide the conversation. Interviewees were asked questions related to three topics: the strategy and model of retrofit practice, collaborative practice and the alignment of their role within the 'ageing in place' agenda.

\section{Data analysis}

The results of the interviews underwent thematic analysis as it allowed for an abductive approach of inquiry (Bowen et al., 2014; Thomas and Harden, 2008). Participants responses were analysed using the 6 phases of thematic analysis outlined by Braun and Clarke (2006) as seen in Figure 3.

Insert Figure 3: Thematic analysis process (Braun and Clarke, 2006)

The first phase involved familiarising oneself with the data, searching for meanings and patterns by becoming immersed in the data. Stakeholder responses were coded for key words, phrases and sentences which indicated recurring, interesting patterns and meaningful units were selected. The codes were then re-focused and analysed at the broader level of conceptual themes. Once themes emerged, these were then reviewed and refined, and the data was analysed within the themes and extracts were selected which illustrated the key themes present. Although no preliminary themes were selected before beginning data analysis, the emerging data was informed and consistently reviewed by a range of current literature and the theoretical framework of institutional theory.

\section{Ethical considerations}

Ethical approval from participants was essential to ensure the integrity of the research was maintained and to guarantee informed consent. The research invitation letter made the aims of the research, participation criteria and data collection methods clear. The invitation for participation also sets out the confidential nature of the data and made it clear that the participant had the right to withdraw at any time during the interview.

\section{Results}

From analyses, five key themes arose: barriers of governance, fragmentation, data infrastructure, dereliction of skills and communication and knowledge share.

\section{Barriers of governance}

The structures of government funding allocation differ between organisations, creating limited efficacy of planned works between state service providers as C1 Councillor states, 
'we're given grants over three years, whereas the Energy Agency (environmental charity) work year to year...there could be good savings to work like external cladding at the same time as roof repairs because the staging is there... we can't plan because we don't know their funding'.

However, C4 ABS comments that there are potential wider issues that could arise from their current funding structures,

'when the Scottish Government come up with a policy or programme to deliver, it's done very quickly...the council suddenly has $£ 2$ million to spend and it has to be spent by the end of the financial year...it's a case of get the money...get the bodies on site... we're doing significant work to people's homes and getting it wrong can be catastrophic'.

Thus, showcasing the potential for detrimental unintended consequences upon the house and resultant health of the resident if proper procedure is not followed; catalysing erratic and absentminded results, due to disregard of the criticality of the task. Furthermore, C4 ABS states that internal arrangements and governance within the SHP inhibits projects, with its vast structure and focus on efficiency, or appearance of efficiency, creating significant obstructions,

'(SHP) have went through a major restructuring...there’s been a lot of uncertainty...we have felt that because you can’t pin anyone down to make a decision or even point you in the direction of who to talk to'.

This feeling is resonated internally within the SHP, as C8 Housing OT reflects, 'I sometimes think of how many times it could have been useful for me to know of that person, but I couldn't until I met them...we have a phone and a directory system, but you have to look them up by name but what happens if you don't know their name? We have the infrastructure but not the information, it's ridiculous, you'd think a big organisation like this would have these things sorted, but no'.

Therefore, this vast structure and lack of communication present within the large SHP creates substantial constrains on the very possibility of integrated retrofit practice, whereby the individual holding the central position linking health and housing, holding a holistic understanding of the interconnections between sectors, has limited visibility and access to the necessary individuals required to create the relationships and partnerships required. 


\section{Fragmentation}

Discussing the integration of retrofit practice between housing, energy and health, a key emergent theme was fragmentation between the sectors, despite being state funded and controlled. This can be understood by C1 Councillor's comments,

'if people are coming out of hospital, we could target those houses, but the problem is that there's a breakdown in communication between health and social care and housing because we don't know who is in hospital, so there needs to be a closer relationship...they report to their bosses, but they should report to us too and that's how you get bed blocking'.

C3 Coordinator comments further on this fragmented practice,

'I’ve seen us identifying a tenant with needs, they require support from an OT, but then it goes into a blackhole...that led to, and it was unfortunate, but we had to allocate the property to someone in normal or mainstream housing because we couldn't afford to wait longer'.

Thus, displaying not only the lack of multidisciplinary communication, but also the central economic pressures social housing providers face; choosing between meeting targets and achieving revenue, which can often result in detrimentally impacting the support and wellbeing of their residents' lives. Moreover, this view was echoed throughout the council, as seen by C2 Director,

'there are wider social issues, because the potential cost to the NHS from delayed discharge could be $£ 25,000$, whereas we could spend $£ 12,000$ on adaptations to get them home, but how do we get those connections?'.

This quote illustrated the impact of silo-based funding and policies, preventing interconnections and fragmenting services when there are mutual benefits. However, there are individuals attempting to combat this barrier, actively making the connections the council cannot, as seen by C4 ABS,

'(ABS) is a joint project with the NHS, they have been very involved in the design and monitoring process'.

Displaying that these meaningful connections and collaborative practice between energy and health can not only be possible, but successful within implementation.

\section{Data infrastructure}

A vital issue which arose within data analysis was the poor infrastructure in place, creating reduced efficiency and increased cost. This is seen within C3 Coordinator's example, 
'I was asked why we weren’t doing EWI to a property, I stated the data said it was already insulated...they had issues of dampness, previous insulation had been removed but never replaced, but our data showed it there... his son was diabetic and they couldn't keep his room warm...I know 16 properties in (location) alone which they declare pass (SHQS/EESH) which wouldn't'.

This issue was further reinforced by Housing OT C8, 'the record will say there is a ramp, but that was taken out and never up-dated...I ask for a wet floor shower, but something changes... what actually happens is different, but our records will still say wet floor shower'.

Displaying the vast extent of this problem, of insufficient recording procedures, impacting not only future planned works but the health and wellbeing of vulnerable residents. This was also experienced externally by C4 ABS,

'the quality of data is questionable...we know 50 houses that had insulation extracted because something went wrong but there is no record of that...cavity wall insulations were put in, but nobody knows where the guarantees are, they don't even know if they were lodged to even exist'.

He then explains a key reason for this is the aversion to systematic procedure and technology in the past,

'they had a person for 30 years, a bank or knowledge, but that is lost, not just skillset, but the information because there are no records...it surprised me how little the council knows about their own stock'.

Therefore, showcasing the deep-rooted difficulties which can be backdated to historic work, and still create substantial problems to-date. If the LA has insufficient data knowledge it can be proffered that this will inhibit not only internal, crossdepartmental collaboration, but also external. It impedes the very possibility of longterm, large-scale adaptation practice as coherent plans cannot be created without trusted baseline data for retrofit practice.

\section{Dereliction of skills}

Following years of austerity cuts few inhouse skills have been retained, resulting in an over reliance upon subcontractors, an issue present across many LA within the UK, as C4 ABS states,

'we've never had particular support from the council in terms of resources...(SHP) outsource everything, they don’t even do their own health and safety anymore, they 
have one full-time and one part-time clerk of works for all council work...we've never been able to rely on them and had to employ our own'.

This displays the prevailing impact and lack of trust in ability of the council within retrofit practice, resulting in an external body having to invest in the program themselves to ensure high standards. However, within the SHP, there is dissatisfaction with these circumstances and a desire for change, with C6 Housing Lead commenting,

'Energy Agency (ABS) are really good at working with us but we need more skills to be honest; to be able to do what we need to do (meeting EESH standards)'.

Contrastingly, others within the SHP believe although changes could be positive, they aren’t necessarily essential, as C8 Housing OT comments,

'I think what matters is how well it works, and it works well... I would lean towards things being in-house, because you have a degree of control and can rely on them because their expectation of added value'.

However, C3 Coordinator is trying to change this practice, seeing the economic and decision-making mistakes, as seen by his introduction of a salaried architect

'his commission was only for planning applications for ramps, so if we wanted a housing warrant for a bathroom adaptation or building warrant, he wasn’t allowed, and we had to get someone else...now it's streamlined, and he does everything'.

Thus, displaying the economic and procedural inefficiencies within the SHP, with a clear lack of joined-up thinking, which could be easily remedied if the impetus is present.

\section{Communication and knowledge sharing between stakeholders}

Following discussion, it emerged that there was serious fragmentation within communication and knowledge share in the SHP, creating increased cost through a disjointed approach to retrofit practice, as C3 Coordinator experienced,

'we were doing fire resistant work, pipes and electrical work were penetrating

walls, property and maintenance went in with expanding foam...it went

everywhere, it was someone who didn’t care and just fired it in...I am now paying

a contractor to clean it out and get back to where we started...none of it was

necessary so it was a massive waste on resources and cash'.

This is again reinforced by his example of, 


\begin{abstract}
'(tenant) had a motorised wheelchair, I discovered from the OT property and maintenance installed a new door with a large threshold...poor chap couldn't get in his own house...its bonkers, the joiner sees the tenant and ramp, yet puts in a door with a threshold you have to step over...no one decides 'wait a minute this is not suitable'...they're just going purely by data or whatever'.
\end{abstract}

Therefore, displaying the need for wider thinking, for tenant focused retrofit which accounts for the needs of all residents, and looks beyond quantitative figures, and to the tenant as an individual. This therefore creates the question of wider thinking, and an overriding focus upon data and orders prevailing above the consideration of tenants and need. This concept of communication across departments has polarised views, with Director C2 stating,

'in years past people were very myopic in terms of what was in front of their noses...now people are reaching out and share practice and knowledge...they understand the opportunities’.

However, C3 Coordinator states,

'it's a thing we've forgotten, we sit in our splendid isolation and fire out an email...go speak to them, understand what they are about and let them understand you'.

Thereafter, displaying opposed views from a strategic to practical view of the levels of communication and knowledge sharing practically implemented within retrofit practice.

\title{
Discussion
}

Deficient of the infrastructure and resolve required for successful communication and joint-working, there are key barriers to cross departmental working within this SHP. Thus, preventing the very possibility of successful external collaboration with aligning bodies. Moreover, as an inherently political body, there is the appearance of a greater focus upon quantitative outcomes for re-election, rather than quality outcomes for the local community. This is visible through the increasing manifestations of negative socioeconomic impacts within housing practice and upon the lives of vulnerable residents. Moreover, it is evident that the infrastructural and governmental barriers presented, coupled with internal and external power struggles emergent from a silobased strategic vision, prevents multidisciplinary action and proactive change. Thereafter, these institutional boundaries must be broken and a recognition must emerge that long-term solutions cannot be created in isolation but through working together; internally and externally across all service providers. Institutions are networks through which political interests interact and compete, therefore shaping and constraining subsequent choices (Hall and Taylor, 1996). State social housing holds a unique position within the sector; government funded and regulated, it must not only care for 
the most vulnerable, but be accountable to the people. Thus, is it imperative that retrofit practice takes a holistic, innovative approach to the cross-sector problems aligned with an ageing population.

The establishment of NPM, coupled with a decade of fiscal restraints due to an ideologically driven austerity agenda has created a target-driven culture that is reluctant to take on institutional responsibility (Heald and Steel, 2018). Through data analysis, it became clear that this agenda and ideology has greatly impacted skills and knowledge within retrofit practice: creating increased pressure and restricting internal and crosssector collaboration through a focus upon calculable outcomes. Institutional theory aids in explaining how both deliberate and inadvertent choices lead organisations to mirror the norms, values and ideologies of the field. As a result, meeting the environment's expected characteristics and receiving legitimacy (Lepsius, 2017). Weber (1958) described these expectations and social pressures as the 'iron cage', where institutions are pushed towards isomorphic forms of normative behaviour; becoming identical to those within the same sector (Lepsius, 2017). Therefore, it could be asserted that Scottish social housing providers follows the concept of mimetic isomorphism (Dimaggio and Powell, 1983), with current practice viewed as successful and legitimate within the field. However, if this fragmented practice is deemed acceptable, as best practice, then there is a vital need for change- for the boundaries and definition of collaboration to be redefined into one which incorporates all aspects of care. There is a need to break through the deep-rooted intrinsic barriers created within the defined boundaries of policy and budget, unto one which creates maintains the wellbeing and prosperity of the population.

Within the concept of Governmentality (1982), Foucault referred to the power struggles felt within neoliberal societies. This is clearly visible within the power relations across the different sectors studied: seeking to protect their budgets and follow direct sectorial rule, therefore releasing responsibility of care upon others. Although emergent from neoliberal practices such as performance benchmarking and increased pressure due to economic restraint, this is accentuated by the institutional structures of silo-based funding, policies and hierarchical structures within the public sector. These highly bureaucratic organisations are resistant to change (Weber, 1958). The prevailing atmosphere of control and predictability favours continuity and is threatened by change and innovation. However, there must be a repositioning in the minds of those implementing retrofit practice, creating a view focused upon the needs of the individual within the wider setting, rather than focusing on individual agendas. These boundaries must be released, and a renewed focus formed within the context of an ageing population and the significant implications for public policy across housing, health, energy and welfare provision realised. Thus, shifting from the management and implementation of a single sector delivery, to an inclusive, integrated, agenda with mutual benefits across the public sector.

\section{Conclusion}

There is a need for greater levels of integration within retrofit practice, not only to improve the wellbeing of the older population, but to increase efficiency and economic savings within public services. Fundamental change must occur in the way in which housing, health and energy sectors interpret themselves; there must be a realisation that all funding, policies and regulations arise from one source, a source with the objective of the maintenance and care of the population. The hierarchical structures with silobased application have created the belief that each sector are separate entities with 
separate agendas, however these are governmental and socially constructed boundaries. These are interlinking agendas, with a much broader economic and social impact and this is particularly significant when looking at successful ageing in place. Therefore, there is a need for a system-wide recognition of the potential benefits of cross-sector collaboration, and a step back from the neoliberal values in place: understanding the potential for reduced cost and dependency upon state through increased knowledge share and collaboration within retrofit practice.

Key areas of future research include undertaking a multiple case study research of social housing providers, with the inclusion of RSL's, within different geographic locations to test emergent theories and increase generalisability across the UK and wider international world. Furthermore, there is a need to examine the perceptions and impacts upon the ageing population residing within social housing to determine their perceptions and the potential for a greater participatory approach to retrofit practice and policy.

\section{References}

Abdul-Aziz, A.R., M., Jaafar., A.R. Nuruddin. and Lai, S.W. (2010), “Using institutional theory and resource-based perspective to aid transformation of housing-related public enterprises in Malaysia”, Habitat International, Vol. 34 No. 2, pp.196-203.

Bowen, P., Y. Allen, P. Edwards, K. Catterl. and Simbayi, L. (2014), “Guidelines for effective workplace HIV/AIDS intervention management by construction firms”, Construction Management and Economics, Vol. 32 No. 4, pp.362-381.

Boyle, F. and Thomson, C. (2016), "Establishing an evidence base for adapting social housing for an ageing population”, Journal of Financial Management of Property and Construction, Vol. 21 No. 2, pp.137-159.

Braun, V. and Clarke, V. (2006), “Using thematic analysis in psychology”, Qualitative Research in Psychology, Vol. 3 No. 2, pp. 77-101.

Bresnen, M. (2010), “Keeping it real? Constituting partnering through boundary objects”, Construction Management and Economics, Vol. 28 No. 6, pp. 615628.

Buser, M. and Carlsson, C. (2016), "What you see is not what you get: single-family house renovation and energy retrofit seen through the lens of sociomateriality”, Construction Management and Economics, Vol. 35 No. 3, pp.276-287.

Care and Repair Scotland. (2013), Conference Report 2013. Care and Repair Scotland. Clapham, D. 2002. “Housing Pathways: A Post Modern Analytical Framework”, Housing, Theory and Society, Vol.19 No.2, pp.57-68. 
DiMaggio, P.J. and Powell, W.W. (1983), “The iron cage revisited: Institutional isomorphism and collective rationality in organizational fields”, American Sociological Review, 147-160.

Eisenhardt, K.M. (1989), “Building theories from case study research.” Academy of Management Review, Vol. 14 No. 4, pp.532-550.

Ejiogu, A., A. Ambituuni, and Ejiogu, C. (2018), “Accounting for accounting’s role in the neoliberalization processes of social housing in England: A Bourdieusian perspective”, Critical Perspectives on Accounting.

Everingham, J.A., J.Warburton., M. Cuthill. and Bartlett, H. (2012), “Collaborative governance of ageing: Challenges for local government in partnering with the seniors’ sector”, Local Government Studies, Vol.38 No.2, pp.161-181.

Foucault, M. (1982), The subject and power, Brighton, Sussex: Harvester Press.

Galbraith, J.R. (1987), Organization design. In J.W. Lorsch. Ed. Handbook of Organizational Behaviour. Englewood Cliffs, NJ: Prentice Hall.

Hall, P. and Taylor, R.C. (1996), "Political science and three new institutionalisms”, Political Studies, Vol.44 No. 5, pp.936-957.

Haveri, A., I. Nyholm, A. RØiseland, and Vabo, I. (2009), “Governing collaboration: Practices of meta-governance in Finnish and Norwegian local governments”, Local Government studies, Vol.35 No.5, pp.539-556.

Hawley, A.H. (1968), Human Ecology, Vol. 4, pp.328-337. In: Sills, D L (Ed). International Encyclopedia of Social Sciences. New York: Macmillan.

Heald, D. and Steel, D. (2018), “The governance of public bodies in times of austerity”, The British Accounting Review, Vol.50 No.2, pp.149-160.

Hood, C. (1991), “A public management for all seasons?”, Public Administration, Vol. 69, pp.3-19.

Jacobs, K., M. Berry, and Dalton, T. (2013), “'A dead and broken system?': 'insider' views of the future role of Australian public housing”, International Journal of Housing Policy, Vol.13 No.2, pp.183-201.

Krøtel, S.M. (2015), “Contracting for energy efficiency: The diffusion of novel contracting practices at local government level”, Local Government Studies, Vol.41 No.5, pp.794-813.

Lepsius, M.R. (2017), Interests and Ideas. Max Weber's Allocation Problem. In: Wendt, C (Eds). Max Weber and Institutional Theory. Springer, Cham. 
Luneburg., F.C. (2012), “Organizational structure: Mintzberg’s framework”, International Journal of Scholarly, Academic, Intellectual Diversti, Vol.14 No.1, pp.1-8.

Miles, R. E., C.C. Snow, A.D. Meyer. and Coleman, H.J. (2011), Organizational strategy, structure, and process. Palo Alto, CA: Stanford University Press.

Mintzberg, H. (1993), Structures in fives: Designing effective organizations, Englewood Cliffs, NJ, US: Prentice-Hall, Inc.

Mullins, D., B. Reid. and Walker, R.M. (2001), "Modernization and change in social housing: The case for an organizational perspective” Public Administration, Vol.79, pp.599-623.

Murphy, P. and Jones, M. (2016), “Building the next model for intervention and turnaround in poorly performing local authorities in England” Local Government Studies, Vol.42 No.5, pp.698-716.

Ofori-Boadu, A.N., M.A. Shofoluwe. and Pyle, R. (2017), “Development of a housing eligibility assessment scoring method for low-income urgent repair programs” International Journal of Building Pathology and Adaptation, Vol.35 No.3, pp.194-217.

Power, E.R. and Bergan, T.L. (2018), “Care and resistance to neoliberal reform in social housing”, Housing, Theory and Society, pp.1-23.

Rasmussen, G.M.G., P.L. Jensen. and Gottlieb, S.C. (2017), “Frames, Agency and institutional change: the case of benchmarking in Danish construction”, Construction Management and Economics, Vol.35 No.6, pp.305-323.

Rummery, K. (2009), “Health Partnerships, healthy citizens? An international review of partnerships in health and social care and patient/user outcomes”, Social Science and Medicine, Vol.69 No.12, pp.1797-1804.

Saidur, R. (2009), “Energy consumption, energy savings and emission analysis in Malaysian office buildings”, Energy Policy, Vol.37 No. 10, pp.4104-4113.

Sanderson, I. (2002), “Evaluation, policy learning and evidence-based policy making”, Public Administration, Vol.80 No.1, pp.1-22.

Scottish Index of Multiple Deprivation. (2016), The Scottish Government.

Scottish Government. (2018), Home Energy Efficiency Programmes for Scotland:

Delivery Report 2016/17, Edinburgh: Scottish Government.

Shelter. (2007), Older people and housing, Shelter. 
Smiley, J.P., S. Fernie. and Dainty, A. (2014), “Understanding construction reform discourses”, Construction Management and Economics, Vol.32 No.7-8, pp.804815.

Suttor, G. (2011), “Offset Mirrors: Institutional paths in Canadian and Australian social housing”, International Journal of Housing Policy, Vol.11 No.3, pp.255-283.

Thomas, J., A. and Harden, A. (2008), "Methods for the thematic synthesis of qualitative research in systematic reviews”, BMC Medical Research Methodology, Vol.8 No. 45.

Van Hees, S., K. Horstman, M. Jansen. and Ruwaard, D. (2017), "Photovoicing the neighbourhood: Understanding the situated meaning of intangible places for ageing-in-place”, Health \& Place, Vol.48, pp.11-19.

Weber, M. (1958), The protestant and the spirit of capitalism. New York: Scribner. Yazdani Mehr, S. and Wilkinson, S. (2018), “Technical issues and energy efficient adaptive reuse of heritage listed city halls in Queensland Australia”, International Journal of Building Pathology and Adaptation, Vol.36 No. 5, pp.529-542.

Youm, J. and Fejock, R.C. (2019). “Interlocal collaboration and local climate protection”, Local Government Studies, pp.1-26.

Yin, R.K. (2009), Case Study Research: Design and Methods, 4ed, Los Angeles, CA: Sage.

Zhang, D., D.C. Chan, L. Niu, H. Liu, D. Zou, A.T. Chan, T.T. Gao, B. Zhong, R.W. Sit. and Wong, S.Y. (2018), "Meaning and its association with happiness, health and healthcare utilization: A cross-sectional study”, Journal of Affective Disorders, Vol.227 pp.795-802. 
Table 1: Key facts for case study selection.

\begin{tabular}{|l|l|l|l|l|l|}
\hline $\begin{array}{l}\text { Population in } \\
\text { LA }\end{array}$ & Size & $\begin{array}{l}\text { Number } \\
\text { of houses }\end{array}$ & EESH & $\begin{array}{l}\text { Number } \\
\text { of RSL's }\end{array}$ & Governance \\
\hline 112,680 & $\begin{array}{l}1,222 \\
\mathrm{Km}^{2}\end{array}$ & 8131 & $94.3 \%$ & 9 & Conservative/Labour \\
\hline
\end{tabular}


Table 2: Interview participants.

\begin{tabular}{|c|c|c|c|}
\hline Code & Gender & Role & Positioning \\
\hline C1 & Male & Councillor & Strategic apex \\
\hline C2 & Male & Director of Place & Strategic apex \\
\hline C3 & Male & Service Coordinator & Technostructure \\
\hline C4 & Male & Area Based Scheme (ABS) Coordinator & Support staff \\
\hline C5 & Male & Head of Property and Maintenance & Middle line \\
\hline C6 & Female & Housing Services Lead & Middle line \\
\hline C7 & Male & Housing Officer & Operational \\
\hline C8 & Female & Housing Occupational Therapist & Operational \\
\hline C9 & Male & Head of Adaptations & Operational \\
\hline
\end{tabular}




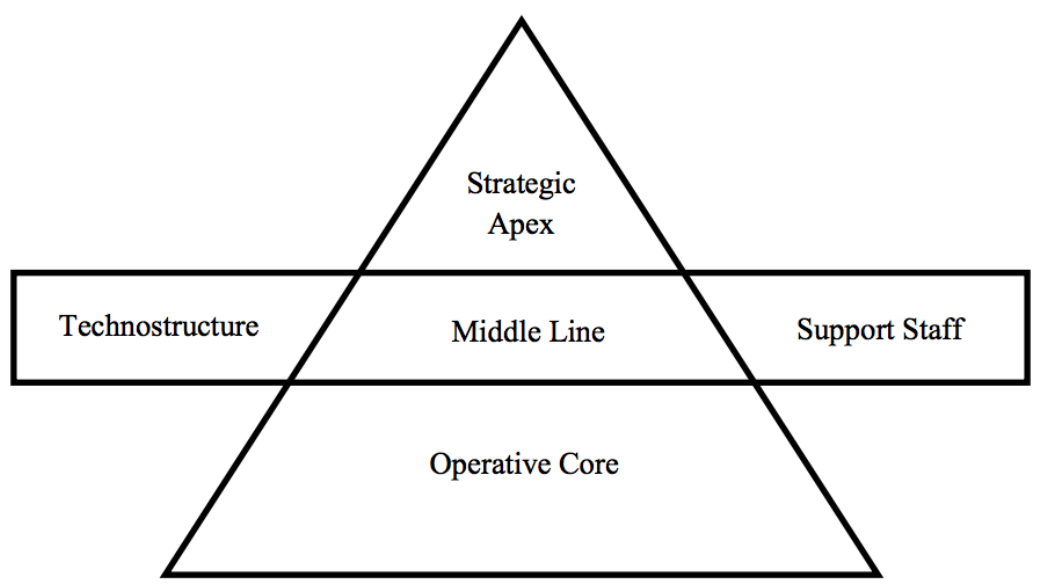

Figure 1: Key parts of an organisation (Mintzberg, 1993). 


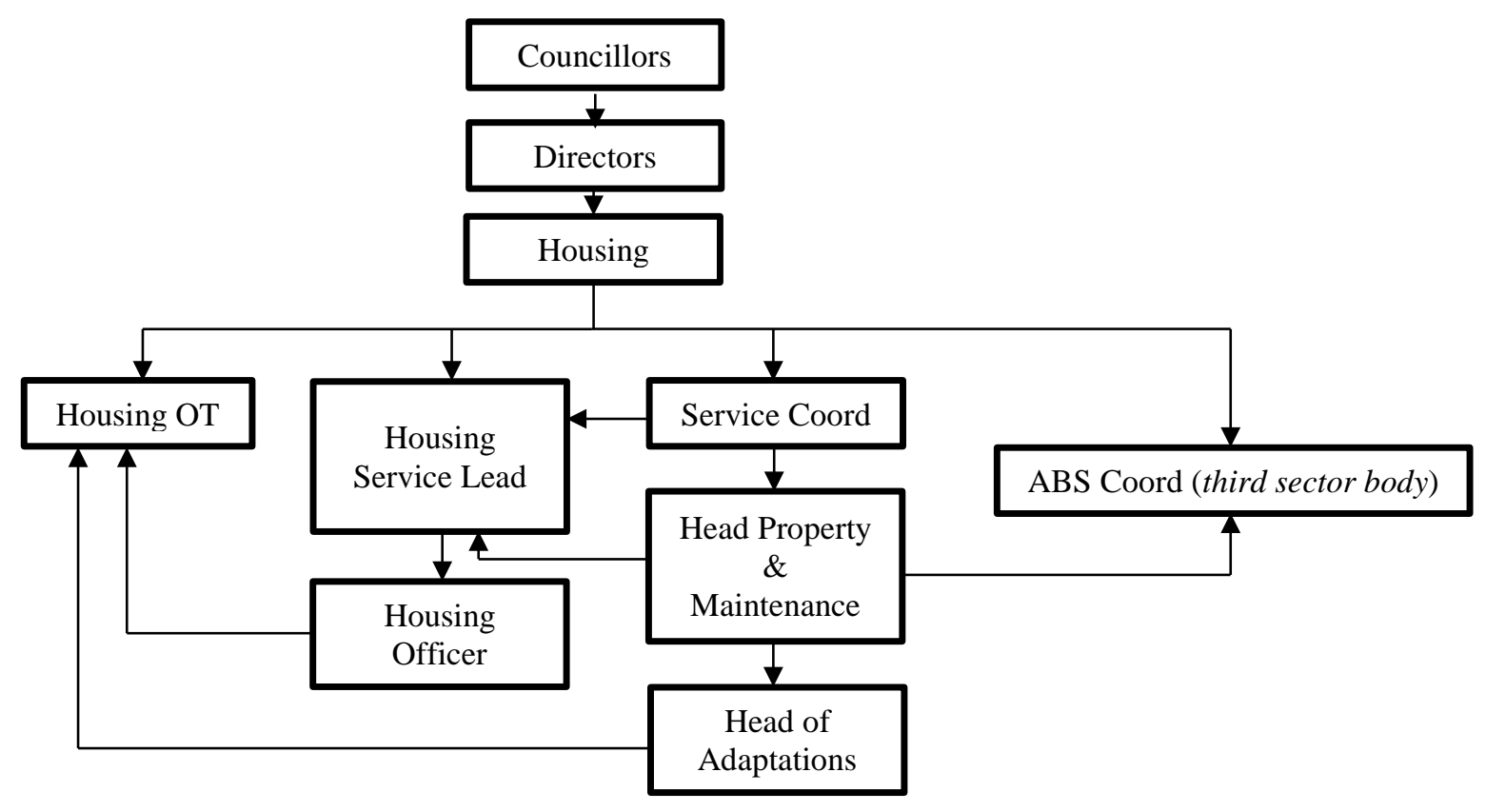

Figure 2. Interview participant hierarchy. 


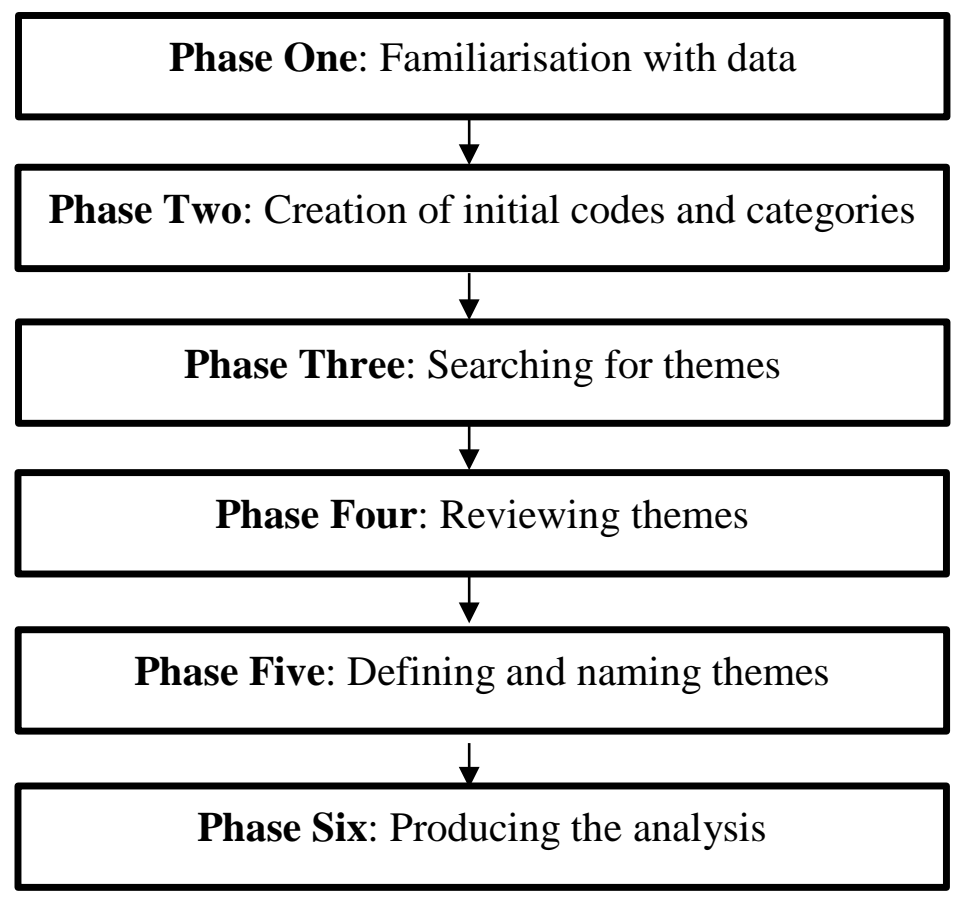

Figure 3. Thematic analysis process (Braun and Clarke, 2006). 